\title{
Does a Spoonful of Sugar-Free Make Food Look Healthier? Healthy Implicit Associations for Sugar-Free and Alternative Products: A Structured Abstract
}

\author{
Patricia Rossi, Marianela Fornerino, and Caroline Cuny
}

\begin{abstract}
Consumers' interest in healthy eating is increasing for a variety of reasons. As a result, several sugar-free and alternative products that use substitute ingredients for sugar are becoming pervasive in supermarket shelves. We investigate consumers' implicit associations between these products and healthiness perception. Drawing on regulatory focus theory, we demonstrate that unhealthy products (e.g., chocolate bar) are associated with healthiness when they rely on labels that highlight the absence (vs. the presence) of a particular ingredient, like sugar-free (vs. milk chocolate). In contrast, healthy products (i.e., orange juice) are associated with healthiness when their labels emphasize the presence (vs. the absence) of a particular ingredient, which is the case of a product with natural juice (vs. sugar-free). We suggest that prevention and promotion focus can explain these effects.
\end{abstract}

References available upon request.

P. Rossi $(\bowtie) \bullet$ M. Fornerino $\bullet$ C. Cuny

Grenoble École de Management, Grenoble, France

e-mail: patricia.rossi@grenoble-em.com; marianela.fornerino@grenoble-em.com;

caroline.cuny@grenoble-em.com 